\title{
Technology Improving Literacy Skills for All Students: Findings from Three Districts
}

\author{
Haya Shamir, Erik Yoder, David Pocklington, and Kathryn Feehan
}

\begin{abstract}
Research has suggested that computer-adaptive curriculum may be an effective means of closing demographic achievement gaps. The current study reports findings for young learners in kindergarten and first grade using a computer-adaptive instruction (CAI) literacy curriculum called the Waterford Early Learning Program (WEL) in three geographically diverse school districts. The aim of the study was to determine how an adaptive, educational technology program targeting early reading skills impacts literacy scores of early elementary school students when used in a traditional classroom setting for just fifteen minutes (for kindergarten students) or thirty minutes (for first and second grade students) per day, five days per week. Experimental students in all three districts used the Waterford Early Learning Program; control students either did not use the Waterford Early Learning Program or had low usage of the program. In all districts, experimental group students benefited from significantly higher gains, percent gains, or end of year scores than control group students. Students in the experimental group from traditionally disadvantaged backgrounds benefited from higher scores. This study shows promise of the efficacy of computer-assisted instruction when utilized in a traditional classroom setting.
\end{abstract}

Index Terms-Blended learning, computer-assisted instruction, literacy, technology.

\section{INTRODUCTION}

An examination of measures of academic success shows that students of minority ethnicities are disproportionately being left behind. In 2015, 21\% of Caucasian students in the fourth grade scored Below Basic on the National Assessment of Educational Progress (NAEP) reading assessment [1]. In the same time period, $48 \%$ of African American students, $40 \%$ of Native Hawaiian and Pacific Islander students, and $45 \%$ of Hispanic students scored Below Basic on the NAEP. Comparable gaps are also present between the NAEP math scores of Caucasian students and students from disadvantaged demographic groups. Dropout rates for African American students (15\%) and Hispanic students $(15.4 \%)$ are nearly double those of their Caucasian peers [2]. Whereas the overall high school graduation rate rose from 2000 to 2010, the graduation rates for African American and Hispanic students are around 8 to 8.5 percentage points lower than that of Caucasian students [3].

The population that is negatively impacted by this achievement gap makes up a meaningful and increasing portion of the American student body [4]. In 2013 Hispanic

Manuscript received May 18, 2018; revised November 15, 2018.

The authors are with the Waterford Research Institute, Sandy, UT 84093 USA (e-mail: hayashamir@waterford.org, erikyoder@waterford.org, davidpocklington@waterford.org,kathrynfeehan@waterford.org). students accounted for $16 \%$ of the overall student body, and in 2015 this percentage rose to $24 \%$. In the same time period, the population of multiracial students doubled from $2 \%$ to 4\%. It has been projected that by 2044 the majority of the student body will be constituted by what are now demographic minorities [5]. Identifying interventions and creating curricula capable of narrowing this achievement gap are necessary actions.

These trends are not only perpetuated but exacerbated throughout an educational career. In 2013, 19\% of Hispanic males between the ages of 25-29 held a bachelor's degree or higher, 23\% of African American males of the same age bracket held a bachelor's degree or higher, and $44 \%$ of Caucasian males of the same age bracket held a bachelor's degree or higher [6]. In 2013, a hypothetical student pursuing a post-baccalaureate degree was $446 \%$ more likely to be Caucasian than to be African American and close to $800 \%$ more likely to be Caucasian than to be Hispanic. Hispanic and African American students are less likely to pursue degrees in STEM fields [7], may be less likely to complete degrees in these fields [8] and are less likely to find employment in these fields after graduating [9]. Research would benefit from exploring methods which could address the achievement gap early in a student's education before lasting damage can be done.

Computer-assisted instruction (CAI) employs educational software and emerging technologies to tailor curriculum and provide meaningful feedback for students in real time [10]. One of the structural benefits of CAI is that a program's expectations for a given student and the feedback it gives that student are built on that student's performance. Whereas there is inevitably a chance that human error will slip into any model for education, with CAI that risk is significantly reduced. When used in conjunction with traditional methods, CAI has been found to lead to better learning outcomes in reading skills [11], math skills [12], and even foster interest in the sciences [13].

Research has pointed to CAI in particular to improve early literacy skills of students in vulnerable populations. A case study of eight African American first graders at risk for learning disabilities found that using CAI curriculum on a weekly basis for four months reduced risk status and increased reading fluency [14]. Randomized trials have shown significant gains on number composition, sub-setting, recognition, arithmetic, and comparison measures for primarily African American and Hispanic students from low-income communities using CAI [15]. Additionally, a study of three geographically diverse and principally African American and Hispanic school districts found that the use of CAI advanced students' study of algebra by a quarter of a 
year [16]. Access to CAI and mobile technology can engage vulnerable students within a lesson plan and lead to better learning outcomes for literacy measures [17]. CAI might be able to provide students with the support and scaffolding necessary to narrow the achievement gap; further research is necessary to ensure its efficacy since the growing population of ethnic minority students has continued to be outperformed by their Caucasian counterparts on average nationally.

\section{METHODS}

\section{A. Participants}

Participants were enrolled in kindergarten, first grade, and second grade classes across three different school districts in Texas, Indiana, and Florida.

\section{1) District 1}

The first district consisted of 4,877 kindergarten, first grade, and second grade students enrolled in a public school district in Texas during the 2015-2016 school year. Approximately $40 \%$ of the students in the district are Hispanic, $30 \%$ are Caucasian, and $15 \%$ are African American.

\section{2) District 2}

The second district consisted of 477 second grade students enrolled in a public school district in Indiana during the 2015-2016 school year. The majority of students in the district are Caucasian, and approximately half of the students qualify for free lunch.

\section{3) District 3}

The third district consisted of 6,131 kindergarten, first grade, and second grade students enrolled in a public school district in Florida during the 2015-2016 school year. The majority of students in the district are Hispanic or Caucasian, and approximately one-half of the students qualify for free lunch.

\section{B. Materials}

\section{1) Waterford early learning program (WEL)}

The program offers a comprehensive computer-adaptive pre-reading and reading curriculum for pre-kindergarten through second grade students. The software presents a wide range of multimedia-based activities in an adaptive sequence tailored to each student's initial placement and his or her individual rate of growth throughout the complete reading curriculum.

\section{2) The Texas primary reading inventory (TPRI)}

The TPRI is an early reading assessment designed to identify the reading development of students in kindergarten through third grade and is administered to students individually. The test identifies students that are at risk for reading difficulties and sets learning objectives for at risk students.

\section{3) Developmental reading assessment (DRA)}

The DRA is a standardized reading test used to determine a student's instructional level in reading. The DRA is administered individually to students by teachers and/or literacy coaches. The test identifies whether the student is below, meeting, or exceeding grade level reading expectations.

\section{4) $V L T$}

The VLT is a county reading and writing test used to determine a student's instructional level in reading and writing according to Florida State Standards in kindergarten, first grade, and second grade.

\section{Procedure}

Kindergarten students were expected to use WEL for fifteen minutes per day, five days per week, throughout the 2015-2016 school year, and first grade and second grade students were expected to use WEL for thirty minutes per day, five days per week, throughout the 2015-2016 school year.

In the first district, the TPRI was administered at the beginning and end of the year. In the second district, schools administered the DRA at the beginning and end of the year. In the third district, the VLT was administered to students at the end of the 2015-2016 school year.

\section{FINDINGS}

For reference, Caucasian students' scores are included in the tables.

\section{A. District 1}

\section{1) Kindergarten}

The analysis includes students who completed the TPRI test at the beginning and at the end of the year. The experimental group for kindergarten $(n=212)$ consisted of students who used WEL throughout the 2015-2016 school year. The control group $(n=1,484)$ consisted of students who did not use WEL during the 2015-2016 school year.

a) Group differences by ethnicity using two-way ANOVAs

Two-way ANOVAs were conducted to examine the effects of WEL and ethnicity on gains for each substrand (see Table I).

1) Letter Name Identification

There was no significant interaction between the effects of ethnicity and WEL on Letter Name Identification gains, $F(5$, $428)=0.947, p=.451$. Simple effects analysis showed that African American and Hispanic students in the experimental group significantly outperformed students in the control group.

\section{2) Letter to Sound Linking}

There was no significant interaction between the effects of ethnicity and WEL on Letter to Sound Linking gains, $F$ (3, $293)=0.01, p=.998$. Simple effects analysis showed that Hispanic students' gains in the experimental group were higher than in the control group, approaching significance. African American students' gains in the experimental group were slightly higher than in the control group, but the difference was not significant.

3) Inferring Word Meaning

There was no significant interaction between the effects of ethnicity and WEL on Inferring Word Meaning gains, $F(5$, $1652)=1.07, p=.373$. Simple effects analysis showed that African American and Hispanic students in the experimental 
group significantly outperformed students in the control group.

\section{4) Linking Details}

There was no significant interaction between the effects of ethnicity and WEL on Linking Details gains, $F(5,1661)=$ $0.44, p=.822$. Simple effects analysis showed that African American and Hispanic students in the experimental group significantly outperformed students in the control group.

5) Recalling Details

There was no significant interaction between the effects of ethnicity and WEL on Recalling Details gains, $F(5,1659)=$ $0.42, p=.838$. Simple effects analysis showed that African American and Hispanic students in the experimental group significantly outperformed students in the control group.

6) Listening Comprehension Total

There was no significant interaction between the effects of ethnicity and WEL on Listening Comprehension Total gains, $F(5,1559)=0.51, p=.766$. Simple effects analysis showed that African American and Hispanic students in the experimental group significantly outperformed students in the control group.

\section{2) First grade}

The analysis includes students who completed the TPRI test at the beginning and at the end of the year. The experimental group for first grade $(n=160)$ consisted of students who used WEL throughout the 2015-2016 school year. The control group $(n=1,391)$ consisted of students who did not use WEL during the 2015-2016 school year.

\section{a) Group differences by ethnicity using two-way ANOVAs}

Two-way ANOVAs were conducted to examine the effects of WEL and ethnicity on gains for each substrand (see Table II).

\section{1) Blending Phonemes}

There was no significant interaction between the effects of ethnicity and WEL on Blending Phonemes gains, $F(3,131)=$ $1.59, p=.196$. Simple effects analysis showed that African American and Hispanic students in the experimental group significantly outperformed students in the control group.

2) Blending Word Parts

There was no significant interaction between the effects of ethnicity and WEL on Blending Word Parts gains, $F(3,289)$
$=1.25, p=.290$. Simple effects analysis showed that African American students in the experimental group significantly outperformed students in the control group. Hispanic students' gains in the experimental group were slightly higher than in the control group, but the difference was not significant.

3) Blends in Final Position

There was no significant interaction between the effects of ethnicity and WEL on Blends in Final Position gains, $F(3,82)$ $=1.49, p=.223$. Simple effects analysis showed that African American students in the experimental group significantly outperformed students in the control group. Hispanic students' gains in the experimental group were slightly higher than in the control group, but the difference was not significant.

4) Deleting Initial Sounds

There was no significant interaction between the effects of ethnicity and WEL on Deleting Initial Sounds gains, $F(3,117)$ $=1.67, p=.177$. Simple effects analysis showed that African American and Hispanic students' gains in the experimental group were slightly higher than in the control group, but the difference was not significant.

5) Final Consonant Substitution

There was no significant interaction between the effects of ethnicity and WEL on Final Consonant Substitution gains, $F(3,156)=2.06, p=.108$. Simple effects analysis showed that African American students in the experimental group significantly outperformed students in the control group. Hispanic students' gains in the experimental group were slightly higher than in the control group, but the difference was not significant.

6) Initial Blending Substitution

A significant interaction was found between the effects of ethnicity and WEL on Initial Blending Substitution gains, $F(3,152)=2.79, p<.05$. Simple effects analysis showed that African American students in the experimental group significantly outperformed students in the control group. Hispanic students' gains in the experimental group were slightly higher than in the control group, but the difference was not significant.

TABLE I: DISTRICT 1 - KINDERGARTEN TPRI GAINS BY ETHNICITY

\begin{tabular}{|c|c|c|c|c|c|c|c|c|c|c|c|c|}
\hline \multirow[t]{3}{*}{ Kindergarten } & \multicolumn{4}{|c|}{ African American } & \multicolumn{4}{|c|}{ Hispanic } & \multicolumn{4}{|c|}{ Caucasian } \\
\hline & \multicolumn{2}{|c|}{ Treatment } & \multicolumn{2}{|c|}{ Control } & \multicolumn{2}{|c|}{ Treatment } & \multicolumn{2}{|c|}{ Control } & \multicolumn{2}{|c|}{ Treatment } & \multicolumn{2}{|c|}{ Control } \\
\hline & $M$ & $S D$ & $M$ & $\overline{S D}$ & $M$ & $S D$ & $M$ & $\overline{S D}$ & $M$ & $S D$ & $M$ & $S D$ \\
\hline Letter Name Identification. & 9.73 & 8.42 & 4.12 & 7.38 & 11.47 & 8.82 & 6.73 & 9.32 & 14.50 & 7.92 & 5.20 & 7.67 \\
\hline Letter to Sound Linking. & 4.14 & 4.34 & 2.33 & 3.36 & 5.00 & 3.25 & 3.11 & 3.72 & 4.50 & 3.42 & 2.67 & 3.73 \\
\hline Inferring Word Meaning. & 0.27 & 0.64 & 0.03 & 0.56 & 0.23 & 0.65 & 0.01 & 0.55 & 0.21 & 0.69 & 0.11 & 0.45 \\
\hline Linking Details. & 0.20 & 0.92 & -0.27 & 0.97 & 0.14 & 1.10 & -0.23 & 1.03 & -0.04 & 0.96 & -0.53 & 0.79 \\
\hline Recalling Details. & 1.77 & 0.68 & 1.42 & 0.72 & 1.63 & 0.81 & 1.42 & 0.80 & 1.37 & 0.88 & 1.24 & 0.67 \\
\hline $\begin{array}{l}\text { Listening Comprehension Total } \\
\text { Score. }\end{array}$ & 2.31 & 1.49 & 1.17 & 1.54 & 2.04 & 1.65 & 1.21 & 1.70 & 1.55 & 1.44 & 0.85 & 1.30 \\
\hline
\end{tabular}

7) Initial Consonant Substitution

There was no significant interaction between the effects of ethnicity and WEL on Initial Consonant Substitution gains, $F(3,253)=1.02, p=.383$. Simple effects analysis showed that African American students in the experimental group significantly outperformed students in the control group. Hispanic students' gains in the experimental group were slightly higher than in the control group, but the difference 
was not significant.

TABLE II: DISTRICT 1 - FIRST GRADE TPRI GAINS BY ETHNICITY

\begin{tabular}{|c|c|c|c|c|c|c|c|c|c|c|c|c|}
\hline \multirow[t]{3}{*}{ First Grade } & \multicolumn{4}{|c|}{ African American } & \multicolumn{4}{|c|}{ Hispanic } & \multicolumn{4}{|c|}{ Caucasian } \\
\hline & \multicolumn{2}{|c|}{ Treatment } & \multicolumn{2}{|c|}{ Control } & \multicolumn{2}{|c|}{ Treatment } & \multicolumn{2}{|c|}{ Control } & \multicolumn{2}{|c|}{ Treatment } & \multicolumn{2}{|c|}{ Control } \\
\hline & $M$ & $S D$ & $M$ & $S D$ & $M$ & $S D$ & $M$ & $S D$ & $M$ & $S D$ & $M$ & $S D$ \\
\hline Blending Phonemes. & 3.00 & 1.58 & 0.69 & 1.23 & 1.87 & 2.13 & 0.88 & 1.53 & 1.50 & 2.12 & 0.44 & 1.00 \\
\hline Blending Word Parts. & 2.67 & 1.56 & 1.33 & 1.48 & 1.79 & 1.77 & 1.58 & 1.66 & 2.17 & 1.33 & 1.29 & 1.40 \\
\hline Blends in Final Position. & 4.00 & 1.41 & 2.00 & 1.93 & 2.30 & 2.00 & 2.04 & 1.65 & 3.67 & 1.53 & 1.11 & 1.37 \\
\hline Deleting Initial Sounds. & 2.75 & 1.50 & 1.07 & 1.76 & 1.80 & 1.82 & 1.12 & 1.99 & 3.50 & 1.00 & 0.76 & 1.45 \\
\hline Final Consonant Substitution. & 1.83 & 2.04 & 0.14 & 0.55 & 1.31 & 1.80 & 1.04 & 1.67 & 0.00 & 0.00 & 0.50 & 0.89 \\
\hline Initial Blending Substitution. & 4.40 & 0.89 & 2.40 & 1.82 & 2.33 & 1.68 & 2.27 & 2.03 & 4.00 & 1.41 & 1.71 & 2.02 \\
\hline Initial Consonant Substitution. & 2.00 & 2.31 & 0.62 & 1.18 & 1.77 & 1.85 & 1.47 & 1.71 & 1.00 & 1.41 & 0.62 & 1.26 \\
\hline Middle Vowel Substitution. & 2.25 & 2.22 & 0.35 & 0.77 & 1.17 & 1.75 & 0.40 & 1.21 & 1.00 & 1.00 & 0.06 & 0.36 \\
\hline
\end{tabular}

TABLE III: DISTRICT 2-SECOND GRADE DRA PERCENT GAINS BY ETHNICITY

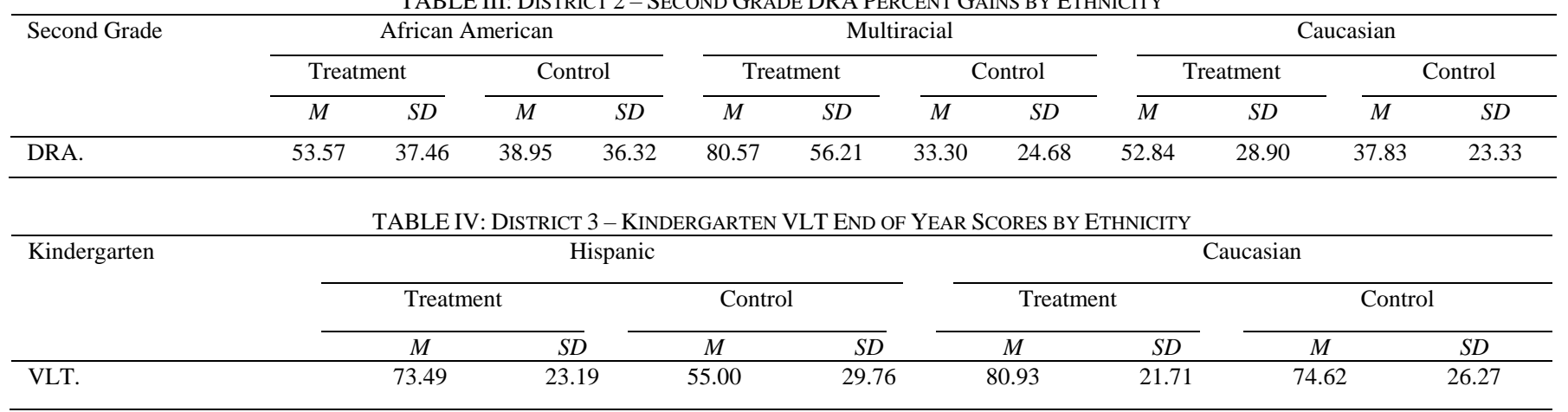

TABLE V: DISTRICT 3 - FIRST GRADE VLT END OF YEAR SCORES BY ETHNICITY

\begin{tabular}{|c|c|c|c|c|c|c|c|c|c|c|c|c|}
\hline \multirow[t]{3}{*}{ First Grade } & \multicolumn{4}{|c|}{ African American } & \multicolumn{4}{|c|}{ Hispanic } & \multicolumn{4}{|c|}{ Caucasian } \\
\hline & \multicolumn{2}{|c|}{ Treatment } & \multicolumn{2}{|c|}{ Control } & \multicolumn{2}{|c|}{ Treatment } & \multirow{2}{*}{\multicolumn{2}{|c|}{$\begin{array}{r}\text { Control } \\
S D\end{array}$}} & \multicolumn{2}{|c|}{ Treatment } & \multicolumn{2}{|c|}{ Control } \\
\hline & $M$ & $S D$ & $\bar{M}$ & $S D$ & $M$ & $S D$ & & & $\bar{M}$ & $S D$ & $\bar{M}$ & $S D$ \\
\hline VLT. & 66.78 & 20.31 & 63.00 & 19.05 & 70.53 & 19.54 & 52.29 & 26.29 & 73.30 & 19.47 & 63.87 & 23.78 \\
\hline
\end{tabular}

8) Middle Vowel Substitution

There was no significant interaction between the effects of ethnicity and WEL on Middle Vowel Substitution gains, F(3, $130)=1.51, p=.216$. Simple effects analysis showed that African American and Hispanic students in the experimental group significantly outperformed students in the control group.

\section{B. District 2}

\section{1) Second grade}

The experimental group for second grade $(n=70)$ consisted of students who used WEL during the 2015-2016 school year. The control group $(n=407)$ consisted of students who did not use WEL during the 2015-2016 school year.

\section{a) Group differences by ethnicity using a two-way ANOVA}

A two-way ANOVA was conducted to examine the effects of WEL and ethnicity on DRA percent gains (see Table III). There was a significant interaction between the effects of ethnicity and WEL on DRA percent gains, $F(4,464)=2.74$, $p<.05$. Simple effects analysis showed that Multiracial students' percent gains in the experimental group were significantly higher than in the control group. African American students' percent gains in the experimental group were slightly higher than in the control group, but the difference was not significant.

\section{District 3}

\section{1) Kindergarten}

The experimental group for kindergarten $(n=1,287)$ included students who used WEL for more than 1,000 minutes throughout the 2015-2016 school year. The control group $(n=43)$ included students who used WEL for less than 500 minutes throughout the 2015-2016 school year.

a) Group differences by ethnicity using a two-way ANOVA

A two-way ANOVA was conducted to examine the effects of WEL and ethnicity on VLT end of year scores (see Table IV). There was no significant interaction between the effects of ethnicity and WEL on VLT end of year scores, $F(3,1319)$ $=2.17, p=.090$. Simple effects analysis showed that Hispanic students in the experimental group significantly outperformed students in the control group.

\section{2) First grade}

The experimental group for first grade $(n=1,892)$ included students who used WEL for more than 1,000 minutes throughout the 2015-2016 school year. The control group $(n=34)$ included students who used WEL for less than 
300 minutes throughout the 2015-2016 school year.

a) Group differences by ethnicity using a two-way ANOVA

A two-way ANOVA was conducted to examine the effects of WEL and ethnicity on VLT end of year scores (see Table $\mathrm{V})$. There was no significant interaction between the effects of ethnicity and WEL on VLT end of year scores, $F(3,1915)$ $=0.70, p=.551$. Simple effects analysis showed that Hispanic students in the experimental group significantly outperformed students in the control group. African American students' end of year scores in the experimental group were slightly higher than in the control group, but the difference was not significant.

\section{CONCLUSION}

Incorporating technology in early childhood education settings can lead to significant academic improvements in young learners [18], [19]. The current study supports previous findings that CAI can be an effective supplement in elementary school curriculum to increase early literacy skills of students. For all three districts, students who used WEL in addition to traditional classroom instruction had significantly higher gains, percent gains, or end of year scores on reading assessments than students who did not use the software. Results from District 3 demonstrated that students who had higher usage performed significantly better than students with less usage.

A key goal in implementing supplemental CAI in a classroom setting is for it to benefit every student, regardless of demographic background. When comparing students within each ethnicity, higher experimental group scores were also reported for students of ethnic minorities, though the improvement was not always significantly higher than the control group. The first district was unique in that the majority of participants were Hispanic, emphasizing that CAI can be used to give students of different backgrounds an equal chance at academic success. This supports previous research which has found positive effects on literacy skills of students of various ethnicities from CAI usage [20], [21].

Future research would benefit from student populations that were more ethnically diverse than the current study. Although the school districts consisted of a large number of students in each grade, there was often not a sufficient number of students of each ethnicity to make meaningful comparisons between the experimental and control groups. The current study was also limited in that literacy improvement was only analyzed throughout the course of one school year. More research on the longitudinal benefits of CAI curriculum as a classroom supplement would help solidify the efficacy of this approach to improving early literacy.

\section{REFERENCES}

[1] National Center for Education Statistics. (2015). NAEP overview. [Online]. Available: http://www.nces.ed.gov/nationsreportcard/about/

[2] D. M. Carpenter and A. Ramirez, "More than one gap: Dropout rate gaps between and among Black, Hispanic, and White students," Journal of Advanced Academics, vol. 19, no. 1, pp. 32-64, Nov. 2007.
[3] R. J. Murnane, "US high school graduation rates: Patterns and explanations," Journal of Economic Literature, vol. 51, no. 2, pp. 370-422, June 2013.

[4] L. Musu-Gillette, J. Robinson, J. McFarland, A. KewalRamani, A. Zhang, and S. Wilkinson-Flicker, "Status and trends in the education of racial and ethnic groups 2016," NCES 2016-007. National Center for Education Statistics, Aug. 2016.

[5] S. L. Colby and J. M. Ortman, "Projections of the size and composition of the US population: 2014 to 2060," Current Population Reports, pp. 25-1143, Mar. 2015

[6] G. Kena, L. Musu-Gillette, J. Robinson, X. Wang, A. Rathbun, J. Zhang, and E. D. V. Velez, "The condition of education 2015. NCES 2015-144," National Center for Education Statistics, May 2015.

[7] National Science Foundation. (June 2012). Women, minorities, and persons with disabilities in science and engineering. [Online] Available: http://www.nsf.gov/statistics/wmpd/race.cfm

[8] P. Arcidiacono, E. M. Aucejo, and V. J. Hotz, "University differences in the graduation of minorities in STEM fields: Evidence from California," American Economic Review, vol. 106, no. 3, pp. 525-562, Mar. 2016.

[9] L. Andersen, and T. J. Ward, "Expectancy-value models for the STEM persistence plans of ninth-grade, high-ability students: A comparison between Black, Hispanic, and White students," Science Education, vol. 98, no. 2, pp. 216-242, Mar. 2014.

[10] R. M. Tamim, R. M. Bernard, E. Borokhovski, P. C. Abrami, and R. F. Schmid, "What forty years of research says about the impact of technology on learning: A second-order meta-analysis and validation study," Review of Educational Research, vol. 81, no. 1, pp. 4-28, Mar. 2011.

[11] P. Macaruso and A. Rodman, "Efficacy of computer-assisted instruction for the development of early literacy skills in young children," Reading Psychology, vol. 32, no. 2, pp. 172-196, Mar. 2011.

[12] S. Demir and G. Başol, "Effectiveness of computer-assisted mathematics education (CAME) over academic achievement: A meta-analysis study," Educational Sciences: Theory and Practice, vol. 14, no. 5, pp. 2026-2035, 2014

[13] H. Kermani and J. Aldemir, "Preparing children for success: Integrating science, math, and technology in early childhood classroom," Early Child Development and Care, vol. 185, no. 9, pp. 1504-1527, Sep. 2015.

[14] L. Gibson, G. Cartledge, and S. E. Keyes, "A preliminary investigation of supplemental computer-assisted reading instruction on the oral reading fluency and comprehension of first-grade African American urban students," Journal of Behavioral Education, vol. 20, no. 4, pp. 260-282, Dec. 2011.

[15] M. E. Foster, J. L. Anthony, D. H. Clements, J. Sarama, and J. M. Williams, "Improving mathematics learning of kindergarten students through computer-assisted instruction," Journal for Research in Mathematics Education, vol. 47, no. 3, pp. 206-232, May 2016.

[16] L. Barrow, L. Markman, and C. E. Rouse, "Technology's edge: The educational benefits of computer-aided instruction," American Economic Journal: Economic Policy, vol. 1, no. 1, pp. 52-74, Feb. 2009.

[17] M. Warschauer, "Laptops and literacy: A multi-site case study," Pedagogies: An International Journal, vol. 3, no. 1, pp. 52-67, Jan. 2008.

[18] C. L. Wood, A. L. Mustian, and Y. Lo, "Effects of supplemental computer-assisted reciprocal peer tutoring on kindergarteners' phoneme segmentation fluency," Education and Treatment of Children, vol. 36, no. 1, pp. 33-48, Feb. 2013.

[19] N. R. Zomer and R. H. Kay, "Technology use in early childhood education: A review of literature," Journal of Educational Informatics, vol. 1, no. 1, pp. 1-25, Dec. 2016.

[20] B. Chambers, R. Slavin, N. Madden, P. Abrami, M. Logan, and R. Gifford, "Small-group, computer-assisted tutoring to improve reading outcomes for struggling first and second graders," The Elementary School Journal, vol. 111, no. 4, pp. 625-640, June 2011.

[21] R. Schechter, P. Macaruso, E. R. Kazakoff, and E. Brooke, "Exploration of a blended learning approach to reading instruction for low SES students in early elementary grades," Computers in the Schools, vol. 32, no. 3-4, pp. 183-200, Oct. 2015.

Haya Shamir was born Haifa, Israel. She received her $\mathrm{PhD}$ from University of Notre Dame in 2002. She has been working at Waterford Research Institute based in Sandy, Utah since 2005, currently serves as chief scientist. She has published research in multiple journals throughout her career. 
Erik H. Yoder was born in Greenwich, Connecticut, USA. He earned a bachelor of arts in psychology and Norwegian from St. Olaf College, Northfield Minnesota, USA, in 2012. He is employed as a research assistant at the Waterford Research Institute, based in Sandy, Utah, USA.

David B. Pocklington was born in Southfield, MI in 1987. He graduated with MS, experimental psychology, Rivier University, Nashua, NH, 2014. He currently works as a research assistant for the Waterford Research
Institute, Sandy, UT. Research interests include computer-assisted instruction and assessment.

Kathryn C. Feehan was born in York, Pennsylvania. She graduated with honors from the University of Pittsburgh with a bachelor of science in psychology and sociology, and she is currently working on her master of science in education at Duquesne University. She currently works at Waterford Research Institute based in Sandy, Utah. 